\title{
Ruptura: a crise da democracia liberal
}

\author{
Manuel Castells \\ Zahar, Rio de Janeiro, Brasil, 2018, 150 p. \\ Julice Salvagni \\ Universidade Federal do Rio Grande do Sul, Porto Alegre, Brasil. \\ Email: julicesalvagni@gmail.com
}

Ao destacar as múltiplas crises da atualidade, Castells põe-se a pensar sobre o que ele chama de uma crise mais profunda, que é a ruptura da relação entre governantes e governados, produzindo a "total decomposição do sistema político [inclusive] do Brasil” (p.8), por exemplo. Tal colapso da democracia liberal enquanto modelo político de representação e governança abre espaço ao pós-liberalismo, sob uma aparente expressão de ordem revestida pelo caos, que figura com partidos nacionalistas, xenofóbicos e críticos à política tradicional. Constata-se, portanto, que se a crise política tem uma dimensão global, apesar das suas especificidades locais, se trata "do colapso gradual de um modelo de representação" (p.10).

Considerando as instâncias do modelo democrático e o árduo percurso de séculos à chegada desta prática institucional, a democracia se consolida por relações de poder social, embora privilegiando as já cristalizadas. Assim, a crise de legitimidade política surge em detrimento ao rompimento do vínculo dos elegidos com os representados. A classe política que, embora pareça divergir, converge quanto a manutenção de um monopólio que é alicerçado pelo voto do povo, amedrontado pela possibilidade de mudança. Paralelo a isso "bancos fraudulentos são salvos com o dinheiro dos contribuintes, enquanto são reduzidos serviços básicos para a vida das pessoas" (p. 14). Tal inconformidade, porém, toma as ruas, muitas vezes sendo recebida forma violenta pela polícia, materializando uma crise de legitimidade que não é da democracia como um todo, mas de um modelo específico de democracia liberal.

No capítulo as raízes da ira,o autor menciona que a globalização da economia "desestruturou economias nacionais e limitou a capacidade do Estado-nação de responder em seu âmbito a problemas que são globais na origem” (p.18), como crises financeiras, violações de direitos, mudanças terrorismo, etc. Essa lógica, de tornar irrestrita e ação do capital e de diminuir a interferência do Estado, tende a aumentar a polarização das desigualdades sociais. Contudo, os governos seguem intervindo nas crises econômicas, usando-se de dinheiro público para salvar o capitalismo, protegendo especuladores e fraudadores, sob a falácia de assegurar ao cidadão um emprego. Isso tudo, além da corrupção sistêmica ao redor do mundo, especialmente ancorada pela política midiática do escândalo, contribuem para a crise de representação que gera autodestruição da legalidade institucional pelo processo político.

Neste contexto, as mensagens simples que transitam nas mídias de massa e nas redes sociais acabam por se transformar em opinião, facilmente conduzida a personalização da política. Há lideranças se atribui a confiança na construção de um projeto de sociedade e, ao contrário, a deslegitimação destes indivíduos (fundamentada em fatos ou inventada) é a recorrente estratégia de destruição do oponente político. Como parte do jogo político, ainda, não raro são difundidas as políticas do medo, fundamentadas no fantasioso retorno ao comunismo que apesar de não ser referido pelo autor, é recorrente no cenário brasileiro -, ou mesmo nas emoções evocadas pelos atos de terrorismo - à luz do que acontece nos Estados Unidos e Europa -, que por vezes são estreitamente 
vinculadas a discursos de islamofobia ou xenofobia produzindo desfechos devastadores na prática da democracia liberal.

Outro importante foco de autodestruição da legitimidade institucional pelo processo político acontece pela via midiática, tanto marcada pelos meios de comunicação em suas incansáveis notícias sobre os escândalos sistêmicos de corrupção, como também pelas redes sociais, que atribui suposta autonomia comunicativa aos cidadãos. Para o autor, em tempos de pós-verdade, "a fragmentação da mensagem e a ambiguidade da comunicação remetem a emoções únicas e pessoais constantemente realimentadas por estratégias de destruição da esperança” (p. 28). Portanto, ao evocar o medo na população, há uma quebra no vínculo entre o pessoal e o institucional, o que facilita a adesão às políticas ultraliberais e conservadoras da extrema-direita levando, por exemplo, um "personagem estrambólico, narcisista e grosseiro como Trump à presidência imperial dos Estados Unidos” (p. 38), e a Jair Bolsonaro à do Brasil.

Ao debruçar-se no hermético período eleitoral que elege Trump, além de ser possível identificar o desgaste inerente à imagem de Hillary Clinton pela aproximação com o establishment político e financeiros, evidencia-se um movimento identitário do cidadão branco respaldado por uma bíblia, uma nação e um fuzil. Neste sentido, e embasados por pronunciamentos oficiais e propostas eleitorais, fortalecem-se grupos racistas, neonazistas e antissemitas, que visam o ataque os imigrantes sem documentos, o direito ao porte de armas e o apoio à polícia, mesmo quando criticada pela repressão racista.

O caso Brexit há fortes semelhanças com o trumpismo, o que leva a crer que a ascensão da extrema direita em meio a um colapso de certa ordem política está distante de ser um fato isolado. Os argumentos mobilizadores que deram um desfecho favorável ao plebiscito urgiam pela "recusa à livre imigração dos cidadãos da União Europeia” (p. 62), especialmente aos advindos do Leste Europeu, deixando subjacente a resistência à dependência dos fluxos globais e à cultura cosmopolita. Contudo, apenas um ano após o Brexit o panorama político britânico se alterou, provocando um aumento no número de assentos dos trabalhistas, a integração de

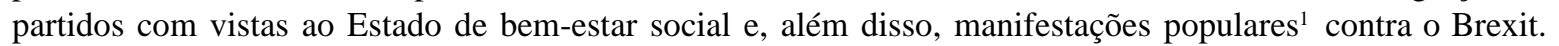
Esses movimentos são importantes mostras do inesperado enfraquecimento do "consenso neoliberal da classe política” (p. 72).

Na França, Emmanuel Macron "decidiu tirar vantagem da divisão e da confusão dos socialistas (...) lançando uma candidatura independente” (p. 75). Assim, ele se elegedada a rejeição maciça aos partidos tradicionais, especialmente porque corresponde ao arquétipo de 'novo líder' pleiteado pelas elites financeiras e tecnocráticas como resposta à crise política. Porém, não apenas ao caso francês, cabe salienta as fragilidades destas supostas novidades que, revestidas pelo neoliberalismo econômico e autoritarismo político, vem sendo apontadas como a "formula de resistência pós-democracia liberal" (p.79). A exemplo dos demais casos, a era Macron também é marcada pela pretexta luta contra o terrorismo e consequente controle dos fluxos migratórios.

O contexto implica em um risco à integração da União Europeia, tão marcada historicamente por conflitos e guerra artroses intencionais à disputa geopolítica pela hegemonia. Após um período de democracia política e respeito aos direitos humanos, Castells sublinha a falta de uma identidade comum ao projeto europeu. Tal situação se instaura a partir dos reflexos da crise de 2008, com restrições de crédito e gastos públicos, além da ocorrência do desemprego em escala. Segundo o autor, a "integração irreversível entre economias desiguais favoreceu os mais poderosos” (p. 89).

Essa análise acaba levando o autor à compreensão de que "quanto mais abstrato de torno o sistema de poder articulado nas redes, mais a defesa do direito a ser se refugia em identidades irredutíveis às lógicas dominantes” (p. 93). Ou seja, essa contradição entre globalização e identidade levou o ator social a não se sentir mais representado pelas instituições, que foram falhas ao gerir a dinâmica entre Rede e o Eu. Assim, Castells destaca a participação dos movimentos sociais autônomos estão cheios de "lições analíticas e lampejos de esperanças” (p. 95), apontando uma direção construtiva à atual crise de representação.

O caso da Espanha, que vinha de uma democracia cansada dado ao bipartidarismo imperfeito com oscilações entre partido de esquerda e direita, sofreu um abalo mais generalizado no início deste jovem século, 
muito em virtude de escândalos de corrupção sistêmica aliada à mídia conspirativa, que reduziam a democracia em partidocracia. Abalado pela crise de 2008 e ao vazio da credibilidade democrática, em 15 de maio de 2011 surge no pais um movimento autônimo e mobilizado pelas redes sociais chamado15-M, carregando pautas em prol da dignidade, igualdade e tolerância. Essa mobilização tornou viável a articulação política doPodemos, marcado pela plurinacionalidade e com diálogo estreito aos movimentos sociais de esquerda, que já vinha conquistando espaços nas bancadas regionais e municipais, até consagrar-se com a vitória à presidência de Pedro Sánchez em 2017.

Um ponto a considerar é que há um novo elemento na construção das democracias, para o bem ou para o mal, que são os espaços virtuais de tratativas, debates da conjuntura e campanha. Talàs eleições brasileiras de 2018 (posteriores à escrita de Castells), a corrida presidencial deTrump, o Brexit ou o caso do espanhol Podemos, o que há em comum, respeitando as muralhas ideológicas que os distinguem, é que o uso múltiplas frentes de plataformas virtuais, que transferem o debate político ao ciberespaço e deixam as mídias tradicionais em segundo plano. Contudo, é assertivo ponderar que há uma dicotomia no uso das mídias: primeiro, e apontado pelo autor, há um tipo de repercussão que pode impulsionar o político mesmo quando é feita de modo negativo, como no caso Trump (e Bolsonaro); ainda, cabe destaque às notícias falsas, não referidas por Castells, mas cujas distorções podem produzir danos irreparáveis à democracia, tanto pela gravidade das calúnias, quanto pelo seu alcance.

De modo geral, a vigente crise de legitimidade política, gerada pela lacuna da representatividade social, tende a agravar-se por uma crise das diferenças, que são fruto da globalização, mas que se opõe àesfera local. Levando em conta que "a densidade histórica e cultural não pode ser ignorada ou reprimida" (p. 141), a saída parcial encontra-se na construção de novos atores políticos e sociais com possibilidade efetiva de rompimento com os modos tradicionais de se compreender as instituições e as identidades, sem que para isso precisem ser cooptados pelo sistema.Enfrentando caudilhos narcisista e seus projetos de injustiça social, a manipulação midiática proferida pelos encantadores de serpentes, a consolidação das máfias no poder, entre outros, abre-se possibilidade para uma nova política, que respaldada pela paciência história, possa recompor a velha utopia autogestionária às demandas contemporâneas.

Por fim, se faz jus umainferência reflexiva sobre a direção cíclica e, ao mesmo tempo, frágil do modelo democrático. Se as transformações do fazer político são emergentes, far-se-á necessário também desconfiar das 'soluções fáceis' ao problemas sociais, já que essas não raro são revestidas por um caráter autoritário, hierárquico e fascista. Sendo o momento sensível à construção de possibilidades, que imperem as vias garantidoras do Estado de bem-estar social, da plena garantia da liberdade de expressão e do respeito à diversidade, igualdade e dignidade humana.

\section{Nota}

\footnotetext{
${ }^{1}$ Para saber mais: https://www.theguardian.com/uk-news/live/2018/oct/20/peoples-vote-march-london-second-referendum-brexitlive?page=with:block-5bcb21e9e4b0c2d58c1b3a4f\#block-5bcb21e9e4b0c2d58c1b3a4f.
} 